\title{
EDUCAÇÃO LÍQUIDA: TECNOLOGIA E EDUCAÇÃO NO SÉCULO XXI
}

\author{
Luiz Antonio Sobreiro Cabreira
}

Universidade do Oeste Paulista - UNOESTE (curso de Pedagogia)

\section{RESUMO}

O presente artigo busca identificar algumas contribuições da tecnologia informacional, refletir sobre as novas formas de produção do conhecimento e da memória social, e sua relação com a construção da educação, como processo de ensino e aprendizagem, nesta fase da modernidade. Procura conceituar a expressão "educação líquida", a partir do pensamento de Bauman, e refletir sobre os desafios da educação, fixada como mercadoria de consumo, diante da nova construção educacional emergente da presença das tecnologias computacionais na educação, a partir de alguns educadores e pensadores como Adorno, Bauman, Villela e Archangelo, entre outros; finalmente pretende pensar sobre a postura docente diante desse processo, Utilizará uma metodologia hipotético-dedutiva, baseada em identificação de novas plataformas educacionais eletrônicas, com abertura para o exercício crítico reflexivo, em alguns momentos, se couber. Não pretende exprimir juízos de valor, antes, refletir sobre as temáticas propostas em torno do $e$ learning, de modo a otimizar o debate crítico a respeito. Tal reflexão se justifica, na medida que se mostra presente a influência de novos recursos de aprendizagem, advindos das tecnologias informacionais, na produção e concepção do conhecimento, no processo de ensino e aprendizagem. O conhecimento destas relações, entre educação e tecnologia, revela-se fundamental para o estabelecimento de um processo educacional consentâneo com as exigências da contemporaneidade e da possibilidade de inovações que conspirem, efetivamente, a favor da condição humana, a partir da ferramenta "educação".

Palavras-chave: educação, tecnologia, modernidade líquida, educação líquida, e-learning.

\section{INTRODUÇÃO E OBJETIVO}

Fulcro central deste trabalho situa-se na reflexão da relação entre educação e tecnologia na sociedade de consumo, denominada por Bauman (2001) de modernidade líquida. Para isso, lança mão de alguns autores como, por exemplo, Adorno (1994), Almeida, Gomes e Bracht (2009), Bauman (1998, 1999, 2001, 2007, 2008, 2010a, 2010b, 2010c, 2011, 2013), Berman (1997), Bittencourt (2011), Calliari e Motta (2012), Di Giorgi (1992, 2004), Lipovetskky (2007), Setton (2011), Villela e Archangelo (2013), entre outros.

Destacam-se os seguintes objetivos

a) identificar algumas contribuições da tecnologia informacional;

b) conceituar a expressão "educação líquida", a partir do pensamento de Bauman; 
c) indicar a nova forma de produção do conhecimento e da memória social, e sua relação com a construção da educação, como processo de ensino e aprendizagem, nesta fase da modernidade;

d) refletir sobre os desafios da educação, fixada como mercadoria de consumo, diante da nova construção educacional emergente da presença das tecnologias computacionais na educação, a partir de educadores e pensadores como Adorno (1994), Bauman (1998, 1999, 2001, 2007, 2008, 2010a, 2010b, 2010c, 2011, 2013), Villela e Archangelo (2013), entre outros;

e) pensar sobre a postura docente diante desse processo.

\section{METODOLOGIA}

O presente artigo, fundamentalmente, uma metodologia hipotético-dedutiva, na identificação de novas plataformas educacionais eletrônicas, com fundamentação teórica estruturada a partir do pensamento de Bauman e outros autores, com abertura para o exercício crítico reflexivo, em alguns momentos da redação do texto.

A utilização de fundamentação teórica e revisão de bibliografia visa consolidar uma postura isenta de pretende exprimir juízos de valor, antes, pretende refletir criticamente sobre as temáticas propostas em torno do e-learning, de modo a otimizar o debate a respeito.

\section{RESULTADOS}

O artigo demonstrou a existência de diversos caminhos para a educação e o processo de formação cognitiva dos estudantes, na modernidade líquida, além da educação formal e tradicional. Abriu um espaço para discutir a questão da influência destas plataformas inovadoras (Seria oportuno citar algumas dessas plataformas) e da educação como mercadoria e objeto de consumo numa sociedade moderno-líquida. Propôs questões adicionais e complementares à questão principal do trabalho. Mostrou que existem riscos na "demonização" ou "santificação" das tecnologias computacionais aplicadas à educação. Registrou e refletiu sobre alguns desafios da educação formal na contemporaneidade e, destacou o fato de que, talvez, o maior problemas nesta discussão não seja o uso ou não das tecnologias, mas, a capacitação para nela se inserir e, com ela, buscar construir uma educação significativa, que conspire a favor da dignidade humana e da cidadania ativa. 


\section{DISCUSSÃO}

A educação líquida pode ser definida como aquela típica deste período de sociedade de consumo, posicionando-se de modo resistente, ou não, às novas qualidades e imposições trazidas pela modernidade líquida à sociedade contemporânea como, por exemplo, a ligação dos sistemas educacionais com as "exigências econômicas de construção do mercado" (TEDESCO, apud GIORGI, 2004).

Uma das características deste período é a emergência de uma mídia comunicacional diferente das anteriores - carta, telefone, rádio, televisão -. Trata-se da internet e das várias possibilidades que esta trouxe ao mundo de interações sociais que estão presentes na sociedade hipermoderna (LIPOVETSKY, 2007) e devotada à globalização planetária.

A educação, entendida aqui como sistema formal de ensino e aprendizagem, estabelecida pelos gestores públicos ou privados, universalizado e consolidado institucionalmente, como as demais instituições sociais, não deixou de receber a influência e participação das novas tecnologias no cotidiano escolar e doméstico de estudantes, professores e gestores educacionais.

Bauman entende que "a 'crise da educação' que tanto se discute em nossos dias não é absolutamente nova" (BAUMAN, 2011, p.112). Mas, para ele, "a crise atual é diferente das demais" (idem), pois se insere num mundo permeado de novas tecnologias, especialmente as tecnologias computacionais, com sua capacidade de "criar" um mundo líquido, flexível, veloz, instantâneo, descartável etc., em que a educação possa ser tomada como um "produto" a ser consumido imediatamente, não mais como um conhecimento sólido e universal, mas fluido ao sabor das exigências do mercado e do interesse hedonista.

Nesse sentido, discutir a relação entre educação e tecnologia computacional deixou de ser uma opção para se configurar como uma necessidade, visto que ambas estão inexoravelmente imbricadas na escola líquida. É o que segue na redação do presente artigo, por meio dos seguintes itens postos para discussão e reflexão:
a) Contribuições tecnológicas para a educação;
b) riscos da "demonização" e "santificação" das tecnologias;
c) questões abertas ainda não respondidas;
d) desafios da educação na modernidade líquida;
e) um produto chamado educação significativa;
f) Quem precisa aprender? 
Numa análise crítica e distanciada da pretensão de formalização de juízos de valor, a evidência da presença do e-learning e das novas configurações que derivaram da influência ativa das novas tecnologias no campo educacional, exige a abertura espaço para o debate crítico a respeito. Tal reflexão se justifica, na medida em que se mostrou inegável a presença e influência de novos recursos, advindos das tecnologias informacionais, na produção e concepção do conhecimento e no processo de ensino e aprendizagem hodierno. O conhecimento destas relações, entre educação e tecnologia, revelou-se fundamental para o estabelecimento de um processo educacional consentâneo com as exigências da contemporaneidade e da possibilidade de reflexões que conspirem, efetivamente, a favor da condição humana, a partir da ferramenta "educação".

\section{CONCLUSÃO}

O artigo evidenciou a distância que existe atualmente entre a proposta tradicional de educação e as novas e inovadoras possibilidades de ensino e aprendizado sob a égide de uma sociedade líquida, marcada pela presença das tecnologias computacionais. Concluiu que o mais relevante não necessariamente é a discussão técnica, política ou didática sobre as vantagens ou desvantagens das tecnologias na educação, mas, numa dimensão democrática e livre do aparato físico e dogmático da educação institucionalizada, ante a efetividade destas novas plataformas na sociedade, perceber que é possível uma escola significativa, com a utilização de recursos tecnológicos. Destaque-se que a educação como mercadoria - reificação da educação - se mostra evidente, além de sinais de dominação de uma ideologia de mercado nas políticas curriculares dos cursos superiores. Questões que emergem e solicitam ampla discussão, no sentido de produzir um processo educacional que conspire a favor das exigências reais da condição humana, antes que da sociedade de consumo.

Uma questão final foi considerada e deve ser refletida com mais vagar, em futuras discussões: trata-se do fato de que, como evidenciou a pesquisadora Léa Fagundes, quem necessita de reformulações na estrutura cognitiva e operacional é o próprio sistema educacional e seus agentes, professores e gestores, já que, ainda muitos não possuem a devida capacitação para utilizar com competência as novas ferramentas e tecnologias computacionais que estão dispostas na sociedade denominada líquida, por Zigmunt Bauman. É necessário lembrar que o estudante deste século XXI é "a primeira geração alfabetizada digitalmente, mais acostumada à falta de roteiros de um programa de entrevista ou reality show do que aos enlatados" (CALLIARI; MOTTA, 
2012, p.31); Fagundes é otimista, como são as linhas do artigo, na medida em que afirma: "[...] eu acredito que futuros professores vão mudar esse cenário, pois são pessoas novas que gostam de tecnologia e não têm medo" (FAGUNDES, 2013, p.2).

Entre os diversos desafios que a educação possui na modernidade líquida, como o fim do monopólio do saber pela escola e a multivocalidade das diversas fontes oriundas das novas tecnologias - plataformas eletrônicas educacionais, e-learnig, a educação e a docência 3.0, o crowdlearning etc. -, é possível que a maior de todos eles não esteja visível externamente, mas, internamente, nos conceitos e posturas dos agentes educacionais frente ao desafio de construir educação de qualidade, alinhado com as exigências e tendências da contemporaneidade.

\section{REFERÊNCIAS}

ADORNO, Theodor W.. Educação após Auschwitz. In Theodor W. Adorno - Sociologia, Coleção Grandes Pensadores, volume 54. São Paulo: Ática, 1994.

ALMEIDA, Felipe Quintão de; GOMES, Ivan Marcelo; BRACHT, Valter. Bauman \& a Educação. Belo Horizonte: Autêntica. 2009.

BAUMAN, Zigmunt. O mal-estar da pós-modernidade. Tradução Mauro Gama e Claudia Mertinelli Gama. Rio de Janeiro: Zahar, 1998.

. Modernidade e Ambivalência. Rio deJaneiro: Zahar. 1999.

. Modernidade Líquida. Tradução Plínio Dentzein. Rio de Janeiro: Zahar, 2001.

. Vida Líquida. Riode Janeiro: Zahar, 2007.

. Los retos de la educación em la moderbnidad líquida. Barcelona, España: Dedisa,

2008.

. Capitalismo parasitário: e outros temas contemporâneos. Tradução Eliana Aguiar. Rio de Janeiro: Zahar, 2010a.

. Lesgisladores e intérpretes. Tradução Aguiar Renato, Rio de Janeiro: Zahar, 2010b.

. Vida a crédito. Tradução Carlos Alberto Medeiros. Rio de Janeiro: Zahar, 2010c.

. As 44 cartas do Mundo Líquido Moderno. Tradução Vera Pereira. Rio de Janeiro:

Zahar, 2011.

Sobre educação e juventude: conversas com Riccardo Mazzeo. Tradução Carlos Alberto Medeiros, Rio de Janeiro: Zahar, 2013. 
BERMAN, Marshall, Tudo que é sólido desmancha no ar: a aventura da modernidade. São Paulo: Companhia das Letras, 1997.

BITTENCOURT, Renato Nunes. A aflição de uma vida líquida. Revista Filosofia. ano V , n.58, p.6-13. abr. 2011.

CALLIARI, Marcos; MOTTA, Alfredo. Código Y: decifrando a geração que está mudando o país. São Paulo: Évora, 2012.

DI GIORDI, Cristiano. Escola Nova. 3. ed., São Paulo: Ática, 1992.

, Uma outra escola é possível. São Paulo: Mercado de Letras/ ALB, 2004.

FAGUNDES, Léa. Educadora de 83 anos defende mudança radical no ensino. Texto publicado em 17/06/2013 no Jornal de Ciência - versão digital. Disponível em:

<http://www.jornaldaciencia.org.br/Detalhe.jsp?id=87600>. Acesso em: 19 jun 2013.

LIPOVETSKY, Giles. A sociedade paradoxal: ensaio sobre a sociedade de hiperconsumo, Tradução Maria Lucia Machado. São Paulo: Companhia das Letras, 2007.

SETTON, Maria da Graça. Mídia e educação. São Paulo: Contexto, 2011.

VILLELA, Fabio C. B.; ARCHANGELO, Ana. Fundamentos da escola significativa. São Paulo: Loyola, 2013. 